\title{
Simultaneous Determination of Mn(II) and Mn(VII) by Single-wall Carbon Nanotubes Preconcentration Hyphenated with ICP-MS
}

\author{
Shizhong Chen*, Li Zhu, Xiuli Chen, Xing Wang, and Xiaorong Zhou \\ College of Chemical and Environmental Engineering, Wuhan Polytechnic University, \\ Wuhan 430023, P. R. China
}

\section{INTRODUCTION}

Due to the rapid development of science and technology, more metals have been used in different industrial and agricultural fields and inevitably discharged into the environment. To evaluate the effects of metals, particularly heavy metals, on the environment, ecosystem and the health of human beings, sensitive, fast, reproducible, simple and accurate analytical methods are often required for the determination of trace elements in environmental samples. Although the detection power of instruments has been greatly improved, the direct determination of trace elements at extremely low concentration levels is often very difficult owing to the insufficient sensitivity of the method, the matrix interferences and contamination in the reagents and/or lab environment. Therefore, matrix separation and preconcentration procedures are often required prior to the measurement step $(1,2)$.

The most common techniques used for the separation and precomcentration of trace elements include solvent extraction, coprecipitation, ion exchange, solid phase extraction, cloud point extraction, adsorption and chromatography (3-9). In comparison with the traditional liquid-liquid extraction method, solid phase extraction provides very attractive features, including simplicity, high preconcentration factors, rapid phase separation, and the ability to use with different detection tech-

\footnotetext{
*Corresponding author.

E-mail: chenshizhong62@163.com
}

\begin{abstract}
Single-wall carbon nanotubes (SWNTs) were used as a new adsorbent for the simultaneous preconcentration and determination of Mn(II) and Mn(VII) by inductively coupled plasma mass spectrometry (ICP-MS). The adsorption behaviors of Mn(II) and Mn(VII) on SWNTs were studied systematically. The results showed that the studied metal ions can be adsorbed quantitatively on SWNTs in a $\mathrm{pH}$ range from 6.0 to 10 . The adsorption capacity of SWNTs is $0.87 \mathrm{mg} \mathrm{g}^{-1}$ for $\mathrm{Mn}$ (II) and $0.53 \mathrm{mg} \mathrm{g}^{-1}$ for $\mathrm{Mn}$ (VII). The main factors influencing adsorption and determination of the analytes have been examined in detail.

Under the optimum conditions, the detection limits for $\mathrm{Mn}$ (II) and Mn(VII) were 0.031 and $0.054 \mathrm{ng} \mathrm{mL}^{-1}$, respectively. The relative standard deviations (RSDs) were $4.2 \%$ and $5.1 \%$ for $\mathrm{Mn}$ (II) and $\mathrm{Mn}$ (VII) ( $\mathrm{n}=9$, $\mathrm{c}=1.5 \mathrm{ng} \mathrm{mL}^{-1}$ ), respectively. The recommended approach was applied for the determination of trace/ultra-trace $\mathrm{Mn}(\mathrm{II}), \mathrm{Mn}(\mathrm{VII})$, and total $\mathrm{Mn}$ in biological and environmental samples with satisfactory results, with recoveries ranging from $94.0 \%$ and $102 \%$.
\end{abstract}

niques (10). It should be pointed out that the sorbent material for solid phase extraction plays an important role in improvement of sensitivity and selectivity of the analytical method. Thus, extensive research for and exploration of new adsorbents for solid phase extraction is important.
In recent years, nanometer-size materials have drawn growing attention in analytical sciences because of their special properties. One of these properties is that most of the atoms of nanoparticles reside on the surface. The surface atoms are unsaturated, possess high chemical activity, and can easily bind with other atoms. Consequently, interest in adapting nanometer material as a new adsorbent for the preconcentration and separation of substance has increased significantly (11-17). Single-wall carbon nanotubes (SWNTs), as an interesting member in the carbon family, have been predicted and experimentally proven to possess exceptional mechanical properties, high chemical stability and a large specific surface area, which make them a promising candidate as an adsorber (18). Another attractive feature is that their surface properties can be modified through chemical treatments to satisfy special requirements (19). All of these facts reveal that SWNTs may have great analytical potential as an effective adsorbent. To our knowledge, however, studies on SWNTs as a solid phase extraction adsorbent for the separation and preconcentration of elements and their speciation have received little attention.

It is well known that the different oxidation states of an element have different effects on human health, the environment and the ecosystems. Manganese exists mainly in Mn(II) and Mn(VII) in the environment. In this work, the adsorption behavior of $\mathrm{Mn}$ (II) and Mn(VII) on SWNTs has been systematically studied, and a new method using a microcolumn 


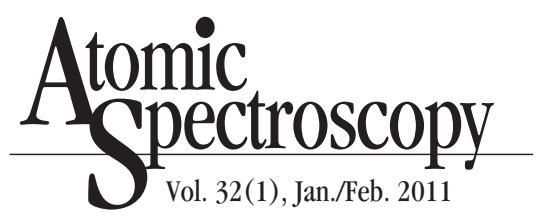

packed with SWNTs coupled to inductively coupled plasma mass spectrometry (ICP-MS) was developed for the simultaneous preconcentration and determination of trace/ultra-trace Mn(II), Mn(VII), or total $\mathrm{Mn}$ in biological and environmental samples with satisfactory results.

\section{EXPERIMENTAL}

\section{Instrumentation}

A Model X-7 ICP-MS system (Thermo Elemental Corporation, USA) with a concentric nebulizer (Meinhard) was used for analyte determination. The optimum operation conditions for the ICP-MS are given in Table I. A model HL-2 peristaltic pump (Shanghai Qingpu Huxi Instrument Factory, P. R. China) coupled to a self-made polytetrafluoroethylene (PTFE) microcolumn ( $40 \mathrm{~mm} \times 3.0 \mathrm{~mm}$ id), packed with SWNTs, was used for the preconcentration/separation process. A minimum length of PTFE tube with an inner diameter of 0.5 mm was used for all connections. The $\mathrm{pH}$ values of the solutions were measured with a $\mathrm{pH}$ meter (Thermo Orion Corporation, U.S.A.) supplied with a combined electrode. An Ethos T microwave digestion device (Milestone, Italy) was used for sample digestion. This device is pressure- and temperaturecontrolled so that on reaching maximum pressure and temperature, the microwave energy input is restricted automatically.

\section{Reagents}

The stock standard solutions of $\mathrm{Mn}$ (II) and In(III) (1.0 $\mathrm{mg} \mathrm{mL}^{-1}$ ) were obtained from the National Analysis Center of Iron \& Steel (Beijing, P.R. China); Mn(VII) was prepared by dissolving $\mathrm{KMnO}_{4}$ (Tianjin Reagent Factory, Tianjin, P.R. China). Working solutions were prepared daily by appropriate dilution of the stock solutions. All reagents used were of ultrapure or

TABLE I

ICP-MS Operating Conditions
Plasma power
Plasma argon flow rate
Auxiliary argon flow rate
Nebulizer argon flow rate
Sampler orifice (nickel)
Skimmer orifice (nickel)
Acquisition mode
Number of sweep
Dwell time
Acquisition time
Number of measurements per peak
Isotope

\author{
$1300 \mathrm{~W}$ \\ $14.5 \mathrm{~L} \mathrm{~min}^{-1}$ \\ 0.72 L min-1 \\ $0.95 \mathrm{~L} \mathrm{~min}^{-1}$ \\ $1.1 \mathrm{~mm}$ \\ $0.7 \mathrm{~mm}$ \\ Peak-jumping \\ 100 \\ $10 \mathrm{~ms}$ \\ $40 \mathrm{~s}$ \\ 3 \\ ${ }^{55} \mathrm{Mn}$ and ${ }^{115} \mathrm{In}$
}

analytical grade. High purity deionized water (18.2 M 2 ) obtained from Milli-Q ${ }^{\mathrm{TM}}$ A10 system (Millipore Corporation, U.S.A.) was used throughout this work.

SWNTs were kindly provided by Shenyang Metal Institute of Chinese Academy (Shenyang, P.R. China). Before use, SWNTs were oxidized with concentrated $\mathrm{HNO}_{3}$ according to the literature (20). The treated SWNTs were dried at $100{ }^{\circ} \mathrm{C}$ and stored for future use.

\section{Column Preparation}

A PTFE microcolumn was filled with $40 \mathrm{mg}$ SWNTs and plugged with a small portion of glass wool at both ends. Before use, $1.0 \mathrm{~mol} \mathrm{~mL}^{-1}$ $\mathrm{HNO}_{3}$ solution and high purity deionized water were passed through the column in order to clean and condition it. Then, the column was conditioned to the desired $\mathrm{pH}$ with a buffer solution.

\section{Sample Pretreatment}

Water samples, collected in Dongxi Lake (Wuhan, P.R. China), were filtered through a $0.22 \mu \mathrm{m}$ membrane filter and analyzed as soon as possible after sampling. A $0.3000 \mathrm{~g}$ amount of pork (GBW 08552 obtained from Geophysical and Geochemical Prospecting, Langfang, P.R. China) was accurately weighed into a $100-\mathrm{mL}$ quartz beaker, then treated with the procedure reported in the literature (21) to prepare the sample containing Mn(VII) for ICP-MS determination. Procedural blanks were performed in the same way.

\section{Procedure}

To study the adsorption behavior of Mn(II) and Mn(VII) ions under dynamic conditions, sample solutions were prepared by the appropriate dilution of the stock solutions and adjusted to the desired $\mathrm{pH}$ with the corresponding buffer solution. The obtained solution was passed through the column by using a peristaltic pump at a desired flow rate. Afterwards, the retained metal ions were eluted with $2.0 \mathrm{~mL}$ of $0.8 \mathrm{~mol} \mathrm{~L}^{-1} \mathrm{HNO}_{3}$. The analytes in the effluents were determined by ICP-MS. Quantification of the elemental concentration was performed using external calibration with aqueous standard solutions and internal standardization using ${ }^{115} \mathrm{In}$ (at $2.0 \mathrm{ng} \mathrm{mL}^{-1}$ in the final solution).

The column could be used repeatedly after regeneration with $1.0 \mathrm{~mol} \mathrm{~L}^{-1} \mathrm{HNO}_{3}$ and deionized water. The recoveries of the analytes were calculated from the ratio of the concentration found by ICPMS to that of the initial sample (>90\%). 


\section{RESULTS AND DISCUSSION}

\section{Effect of $\mathrm{pH}$ on Adsorption}

After oxidization with concentrated $\mathrm{HNO}_{3}$, some acidic groups such as $-\mathrm{COOH}$ and $-\mathrm{OH}$ can form on the surface of SWNTs (19, 20). Hence, the adsorption of ions on SWNTs is highly dependent on the solution $\mathrm{pH}$ value, which affects the surface charge of the adsorbent and the degree of ionization and speciation of the adsorbates. In order to evaluate the $\mathrm{pH}$ dependence of the adsorption, the $\mathrm{pH}$ values of the sample solutions were adjusted to a range of 1.0-10 with $\mathrm{HNO}_{3}$ or $\mathrm{NH}_{4} \mathrm{OH}$. The effect of $\mathrm{pH}$ value on the recoveries of the analytes are shown in Figure 1 , which indicates that the adsorption of the studied ions was quantitative $(>90 \%)$ in the $\mathrm{pH}$ range 6.0-10. Thus, a $\mathrm{pH}$ of 8.0 was used in this work.

\section{Effect of Eluent Concentration and Volume}

A satisfactory eluent should effectively elute the adsorbed analytes with a small volume (which is needed for a higher enrichment factor) and should not affect the accurate determination of analytes.
From Figure 1 it can be seen that the adsorption of the analytes on SWNTs could be negligible at $\mathrm{pH}$ $<3$.0. For this reason, various concentrations of $\mathrm{HNO}_{3}$ were explored as the eluent for the desorption of the retained analytes from the microcolumn. The results in Table II show that 0.8 mol L-1 $\mathrm{HNO}_{3}$ was sufficient for quantitative elution and recoveries (>90\%). The effect of the eluent volume on the recoveries of analytes was also studied by keeping $\mathrm{HNO}_{3}$ concentration at $0.8 \mathrm{~mol} \mathrm{~L}^{-1}$. The results show that $2.0 \mathrm{~mL}$ of $0.8 \mathrm{~mol} \mathrm{~L}^{-1} \mathrm{HNO}_{3}$ is sufficient for the complete elution with the quantitative recoveries (>90\%).

\section{Choice of Sample Flow Rate}

The effect of sample flow rate on the adsorption of the analytes was examined by passing $20 \mathrm{~mL}$ of sample solution through the microcolumn. The flow rates were varied from $0.3-2.0 \mathrm{~mL} \mathrm{~min}^{-1}$. It was found that with flow rates up to $1.0 \mathrm{~mL} \mathrm{~min} \mathrm{~m}^{-1}$, there is no obvious effect on the analyte recoveries (Figure 2). However, the recoveries of the analytes decreased as the flow rate increased over $1.0 \mathrm{~mL} \mathrm{\textrm {min } ^ { - 1 }}$ due to a decrease in the adsorption kinetics. Thus, a flow rate of $1.0 \mathrm{~mL} \mathrm{~min}{ }^{-1}$ was selected in this work.

TABLE II

Eluent Efficiency (\%) for the Analytes from the SWNTs

\begin{tabular}{ccc}
\hline $\begin{array}{c}\text { Eluent }^{\mathrm{a}} \\
\left(\mathrm{HNO}_{3}, \text { mol L L }^{-1}\right)\end{array}$ & $\begin{array}{c}\mathrm{Mn}(\mathrm{II}) \\
\text { (\% Recovery) }\end{array}$ & $\begin{array}{c}\mathrm{Mn}(\mathrm{VII}) \\
\text { (\% Recovery) }\end{array}$ \\
\hline 0.2 & 79.3 & 75.2 \\
0.4 & 84.5 & 81.5 \\
0.6 & 87.9 & 85.6 \\
0.8 & 95.0 & 94.0 \\
1.0 & 98.1 & 97.5 \\
1.2 & 96.3 & 95.4
\end{tabular}

${ }^{\mathrm{a}}$ Eleuent volume: $2.0 \mathrm{~mL}$; $\mathrm{Mn}(\mathrm{II})$ and $\mathrm{Mn}(\mathrm{VII}): 8.0 \mathrm{ng} \mathrm{mL}^{-1}$.

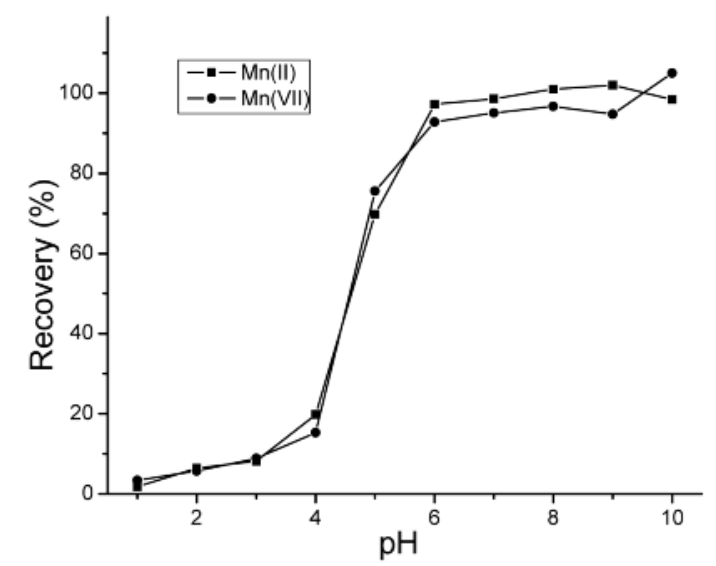

Fig. 1. Effect of $p H$ on recovery of the analytes on $S W N T$. $\mathrm{Mn}(\mathrm{II})$ and Mn(VII): $8.0 \mathrm{ng} \mathrm{mL}^{-1 ;}$; sample volume: $20 \mathrm{~mL}$

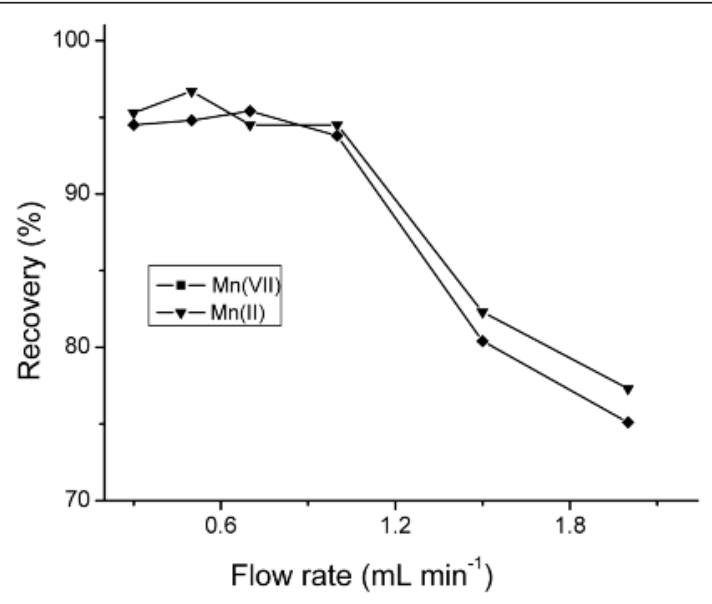

Fig. 2. Effect of sample flow rate on recovery of the analytes from the SWNTs. $p H=8.0 ; \mathrm{Mn}(\mathrm{II})$ and Mn(VII): $8.0 \mathrm{ng} \mathrm{mL}^{-1}$; sample volume: $20 \mathrm{~mL}$. 


\section{Atomic Spectroscopy \\ 1 Vol. 32(1), Jan./Feb. 2011}

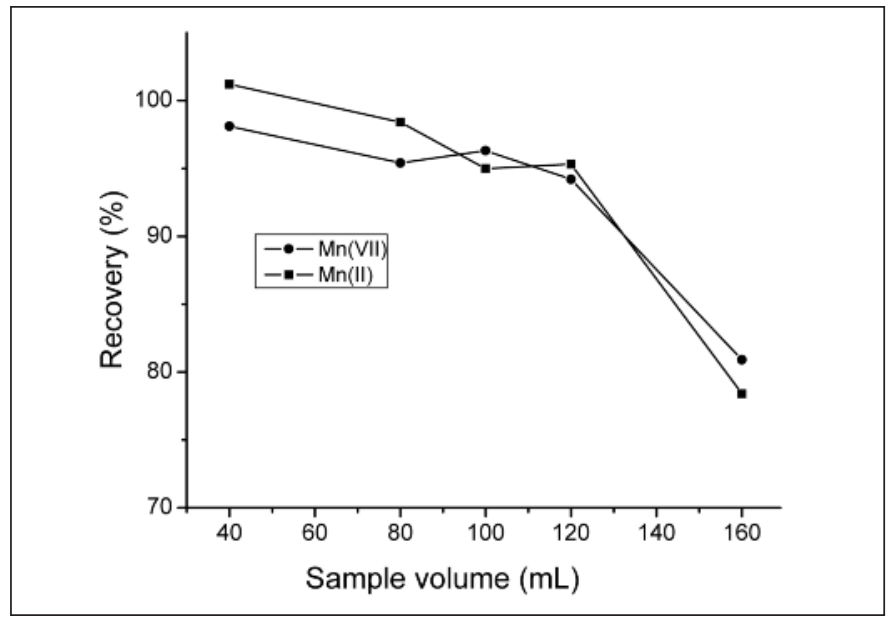

Fig. 3 Effect of sample volume on recovery of the analytes from SWNTs. $p H=8.0 ; \mathrm{Mn}(\mathrm{II})$ and $\mathrm{Mn}$ (VII): $8.0 \mathrm{ng}$; sample volume : $20 \mathrm{~mL}$.

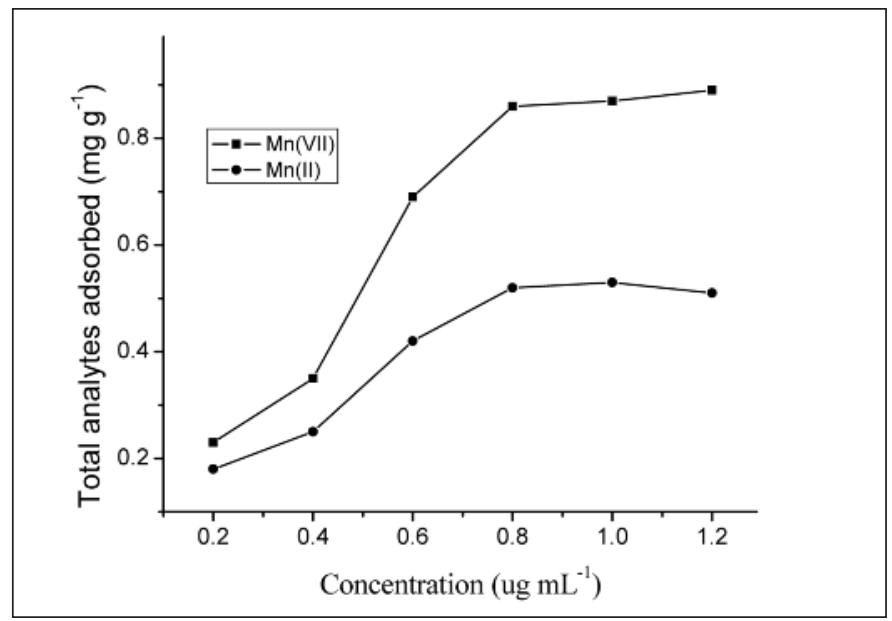

Fig. 4 The breakthrough curve of the analytes on SWNTs. pH=8.0; sample volume.: $20 \mathrm{~mL}$.

\section{Effect of Sample Volume}

The influences of sample volume on the analyte adsorption were investigated in the ranges of $40-160 \mathrm{~mL}$ of the sample solutions containing $8.0 \mathrm{ng}$ of the studied ions. The experimental results in Figure 3 show that the recoveries are quantitative ( $>90 \%$ ) up to $120 \mathrm{~mL}$ of the sample. Therefore, the highest preconcentration factor was 60 when the adsorbed ions were eluted with $2.0 \mathrm{~mL}$ of $0.8 \mathrm{~mol} \mathrm{~L}^{-1} \mathrm{HNO}_{3}$.

\section{Adsorption Capacity}

The adsorption capacity for SWNTs was investigated by the method as proposed in the literature (22). Twenty-mL aliquots of a series of concentrations (0.2-1.2 $\left.\mu \mathrm{g} \mathrm{mL}^{-1}\right)$ were adjusted to the appropriate $\mathrm{pH}$, then preconcentrated and eluted according to the procedure described above. The quantity of metal ions adsorbed at each concentration level was determined. Breakthrough curves were established by plotting the metal ion concentrations $\left(\mu \mathrm{g} \mathrm{mL}^{-1}\right)$ versus the milligrams of metal ions adsorbed on per gram of adsorbent (Figure 4). According to the literature (22), the calculated adsorption capacity of SWNTs from the breakthrough curve is $0.87 \mathrm{mg} \mathrm{g}^{-1}$ and $0.53 \mathrm{mg} \mathrm{g}^{-1}$ for $\mathrm{Mn}(\mathrm{II})$ and $\mathrm{Mn}(\mathrm{VII})$, respectively.

\section{Column Reuse}

The stability and potential regeneration of the column were examined. The column can be reused after regeneration with $10 \mathrm{~mL}$ of $1.0 \mathrm{~mol} \mathrm{~mL}^{-1} \mathrm{HNO}_{3}$ and $20 \mathrm{~mL}$ deionized water and is stable up to 40 adsorption-elution cycles without obvious decrease in the recoveries for the analytes (>90\%).

\section{Effect of Coexisting Ions}

The effects of ions commonly found in environmental samples on the adsorption of the Mn(II) and $\mathrm{Mn}$ (VII) were tested. For this purpose, the concentrations of the interfering ions were varied, whereas the concentration of the analytes was kept at $8.0 \mathrm{ng} \mathrm{mL}^{-1}$. The effects of interfering ions on the recoveries of analytes are given in Table III. It can be seen that the major cations and anions do not interfere with the determination in the range tested.

\section{Detection Limit and Precision}

According to the definition of IUPAC, the detection limits (DL), calculated from three times the standard deviation of the blank signal for Mn(II) and Mn(VII) at $\mathrm{m} / \mathrm{z}$ 55 , were 0.031 and $0.054 \mathrm{ng} \mathrm{mL}^{-1}$, respectively, with an enrichment factor of 60; the relative standard deviations (RSDs) were $4.2 \%$ and $5.1 \%$ for Mn(II) and Mn(VII) ( $\mathrm{n}=9$, $\mathrm{c}=1.5 \mathrm{ng} \mathrm{mL}^{-1}$ ), respectively.

TABLE III

Effect of Coexisting Ions

\begin{tabular}{lr}
\hline $\begin{array}{l}\text { Coexisting } \\
\text { Ion }\end{array}$ & $\begin{array}{r}\text { Concentration } \\
\text { Ratio }\end{array}$ \\
\hline $\mathrm{Na}^{+}, \mathrm{K}^{+}$ & 5000 \\
$\mathrm{Ca}^{2+}, \mathrm{Mg}^{2+}$ & 500 \\
$\mathrm{Al}^{3+}, \mathrm{Fe}^{3+}$ & 50 \\
$\mathrm{SO}_{4}^{2-}, \mathrm{PO}_{4}^{3-}, \mathrm{SiO}_{3}{ }^{2-}$ & 2000 \\
\hline
\end{tabular}

${ }^{a}$ Concentration ratio: Foreign ion/studied ion; recoveries $>90 \%$. 


\section{Sample Analysis}

In order to verify the reliability of the procedure, the method was applied to the determination of $\mathrm{Mn}$ (II) and Mn(VII) in a pork standard reference material (GBW 08552) and environmental water samples. The data obtained are summarized in Tables IV and V. As can be seen, the determined values are in good agreement with the certified values, and the recoveries were between $94.0 \%$ and $102 \%$.

\section{CONCLUSION}

Single-wall carbon nanotubes (SWNTs) were used as a novel solid-phase extraction adsorbent packed in a microcolumn for the preconcentration of $\mathrm{Mn}$ (II) and Mn(VII). The adsorption behavior of $\mathrm{Mn}$ (II) and Mn(VII) on SWNTs was investigated systematically by inductively coupled plasma mass spectrometry (ICP-MS). The analytes were concentrated 60 times and recovered with high precision. The analytes retained on SWNTs can be easily desorbed. The proposed method is suitable for the preconcentration and determination of trace/ultra-trace Mn(II), $\mathrm{Mn}$ (VII) and total Mn in environmental water samples.

\section{ACKNOWLEDGMENT}

This work was supported by the Nature Science Foundation and the Education Department Foundation of Hubei Province, P.R. China.

Received September 3, 2010.

\section{REFERENCES}

1. V. A. Lemos, L. S. G. Teixeira, M. A. Bezerra, A. C. S. Costa, J. T. Castro, L. A. M. Cardoso, D. S. de Jesus, E. S. Santos, P. X. Baliza, and L. N. Santos, Appl. Spectrosc. Rev. 43, 303 (2008).

2. V. Camel, Spectrochim. Acta Part B 58, 1177 (2003).

TABLE IV

Analytical Results and Recoveries of Mn(II) and Mn(VII) in Water Samples

\begin{tabular}{lcccc}
\hline Sample & \multicolumn{2}{c}{ Added $^{\mathrm{a}}$} & Found $^{\mathrm{b}}$ & Recovery(\%) $^{*}$ \\
& $\mathrm{Mn}(\mathrm{II})$ & $\mathrm{Mn}(\mathrm{VII})$ & & \\
\hline Lake Water $\left(\mathrm{ng} \mathrm{mL}^{-1}\right)$ & 0 & 0 & $1.82 \pm 0.11$ & - \\
& 0 & 5.0 & $6.59 \pm 0.41$ & 95.4 \\
& 5.0 & 0 & $6.73 \pm 0.38$ & 98.2 \\
& 0 & 10 & $11.9 \pm 0.57$ & 101 \\
& 10 & 0 & $11.5 \pm 0.49$ & 96.8 \\
\hline
\end{tabular}

${ }^{\mathrm{a}}$ Added after sample pretreatment. $\quad{ }^{\mathrm{b}}$ Mean value \pm standard deviation, $\mathrm{n}=3$.

TABLE V

Analytical Results and Recoveries of Mn(II) and Mn(VII) in the Pork

\begin{tabular}{lccccc}
\hline Sample & \multicolumn{2}{c}{ Added $^{\mathrm{a}}$} & Found $^{\mathrm{b}}$ & Certified & Recovery(\%) \\
& Mn(II) & Mn(VII) & & & \\
\hline Pork $\left(\mu \mathrm{g} \mathrm{g}^{-1}\right)$ & 0 & - & $0.52 \pm 0.08$ & $0.48 \pm 0.09$ & - \\
& 0.5 & - & $0.99 \pm 0.08$ & & 94.0 \\
& 1.0 & - & $1.49 \pm 0.15$ & & 97.2 \\
& - & 0 & $0.55 \pm 0.10$ & $0.48 \pm 0.09$ & - \\
& - & 0.5 & $1.06 \pm 0.13$ & & 102 \\
& - & 1.0 & $1.53 \pm 0.14$ & - & 98.1 \\
\hline
\end{tabular}

${ }^{\mathrm{a}}$ Mean value \pm standard deviation, $\mathrm{n}=3 . \quad{ }^{\mathrm{b}}$ Added after sample retreatment.

3. V. Clatt and J. Kunze, At. Spectrosc. 30(6), 185 (2009).

4. V. Jobbágy, I. Chmielewska, T. Kovács, and S. Chałupnik, Microchem. J. 93(2), 200 (2009).

5. P. Smichowski, L. Valiente, and A. Ledesma, At. Spectrosc. 23(3), 92 (2002).

6. L. A. Escudero, L. D. Martinez, J. A. Salonia, and J. A. Gasquez, Microchem. J. 95(2), 164 (2010).

7. H. Avci, and M. Yaman, At. Spectrosc. 27(4), 117 (2006).

8. C. B. Hymer and J. A. Caruso, J. Chromatogr. A 1045, 1 (2004).

9. R. A. Gil, J. A. Salonia, J. A. Gásquez, A. C. Olivieri, R. Olsina, and L. D. Martinez, Microchem. J. 95(2), 306 (2010).

10. K. Pyrzynska, Crit. Rev. Anal. Chem. 29, 313 (1999).

11. A. Ramesh, B. A. Devi, H. Hasegawa, T. Maki, and K. Ueda, Microchem. J. 86(1), 124 (2007).

12. Y. Cai, G. Jiang, J. Liu, and Q. Zhou, Anal. Chem. 75, 2517 (2003).
13. Q. Zhoua, X. Zhaoa, and J. Xiao, Talanta 77, 1774 (2009).

14. J. C. Stokes and M. E. Johnson, Microchem. J. 76(1-2), 121 (2004).

15. D. Chen, B. Hu, M. He, and C. Huang, Microchem. J. 95(1), 90 (2010).

16. S. Chen, M. Xiao, D. Lu, and X. Zhan, Rapid Commun. Mass Spectrom. 21, 2524 (2007).

17. Y. Cui, X. Chang, Y. Zhai, X. Zhu, $\mathrm{H}$. Zheng, and N. Lian, Microchem. J. 83(1), 35 (2006).

18. D. Eva, O. Saldador, and V. Aurelio, J. Coll. Inter. Sci. 305(1), 7 (2007).

19. Y. Chen, R. C. Haddon, and R. E. Smalley, J. Mater. Res. 13(9), 2423 (1998).

20. Y. Li, S. Wang, Z. Luan, J. Ding, C. $\mathrm{Xu}$, and $\mathrm{D}$. Wu, Carbon 41, 1057 (2003).

21. A. Xue, S. Qian, and J. Huang, Environ. Sci. Tech. 4, 32 (2000).

22. A. Maqieira, H. A. M. Elmahadi, and R. Puchades, Anal. Chem. 66, 3632 (1994). 